\title{
Effects of nitric oxide on zinc tolerance of the submerged macrophyte Hydrilla verticillata
}

\author{
Songhe Zhang ${ }^{1, *}$, Kaihui Liu ${ }^{1}$, Xiaoyang Lv ${ }^{1}$, PeiFang Wang ${ }^{1, *}$, Chao Wang ${ }^{1}$, \\ Wenjing Zhang ${ }^{1}$, ZhenLi He ${ }^{2}$
}

\begin{abstract}
${ }^{1}$ Key Laboratory of Integrated Regulation and Resource Development on Shallow Lakes of Ministry of Education, College of Environment, Hohai University, Xikang NO.1, Nanjing 210098, Jiangsu Province, PR China

${ }^{2}$ University of Florida, Institute of Food and Agricultural Sciences, Indian River Research and Education Center, 2199 South Rock Road, Fort Pierce, FL 34945, USA
\end{abstract}

\begin{abstract}
Heavy metal pollution has become an increasingly recognized threat to the aquatic environment. In response to heavy metal stresses, various terrestrial plants produce the hormone nitric oxide (NO), but minimal information is available about the role of NO in aquatic macrophytes under high zinc (Zn) stress. In this study, we measured physiochemical parameters in the leaves of Hydrilla verticillata exposed to $\mathrm{Zn}^{2+}\left(10 \mathrm{mg} \mathrm{l}^{-1}\right)$ alone or combined with $\mathrm{NO}$ (supplied as sodium nitroprusside, SNP) for $1 \mathrm{~d}$ and $4 \mathrm{~d}$. Excess $\mathrm{Zn}$ disturbed nutrient uptake and altered the redox status of the aquatic plants. NO application partially reversed negative impacts of Zn stress on the contents of photosynthetic pigments, malondialdehyde, nutrient concentration, ascorbic acid, and the activity of antioxidant enzymes. However, the metabolites of SNP did not have similar effects. After treatments for $4 \mathrm{~d}$, plants were further cultured in a solution containing $\mathrm{Zn}^{2+}$ $\left(10 \mathrm{mg} \mathrm{l}^{-1}\right)$ for $10 \mathrm{~d}$. NO application partially reversed $\mathrm{Zn}$-induced negative effects in parameters such as nutrient uptake, antioxidant enzymatic activities, and biomass, as compared to treatments with Zn alone. These results indicate that NO supply could mitigate Zn stress in $H$. verticillata, as a defense mechanism of the plant against $\mathrm{Zn}$ toxicity.
\end{abstract}

KEY WORDS: Nitric oxide $\cdot$ Hydrilla verticillata $\cdot$ Malondialdehyde $\cdot$ Antioxidant response $\cdot$ Zinc

\section{INTRODUCTION}

Zinc (Zn) is an essential nutrient element for plants, as it is the component of many proteins such as $\mathrm{Zn}$ finger-containing transcription factors, $\mathrm{Cu} / \mathrm{Zn}$ superoxide dismutase, carbonic anhydrase and Zn-metalloproteases (Broadley et al. 2007). Many of these proteins have critical roles in the uptake and transport of $\mathrm{Zn}$, transcriptional regulation, RNA binding, regulation of apoptosis and protein-protein interactions (Beyersmann \& Haase 2001, Ciftci-Yilmaz \& Mittler 2008). However, excess $\mathrm{Zn}$ can cause damage to plants. High $\mathrm{Zn}$ affects mitotic activity of cells, photosynthesis, membrane integrity and permeability, and can even kill cells (Stoyanova \& Doncheva 2002, Rout

${ }^{*}$ Corresponding authors:

shzhang@hhu.edu.cn, pfwang2005@hhu.edu.cn
\& Das 2003). Zn toxicity can result in nutrient imbalance and induce the generation of excess reactive oxygen species (ROS, including superoxide radical and hydrogen peroxide), which cause oxidative stress and lipid peroxidation (Wang et al. 2009). These negative effects may contribute to the inhibition of seed germination, plant growth and root development (Wang et al. 2009).

Plants have developed innate complex resistance/ adaptation mechanisms such as antioxidant systems to help them survive in the altered environment. Antioxidant enzymes like superoxide dismutase (SOD), ascorbate peroxidase (APX), catalase (CAT) and guaiacol peroxidase (POD), as well as antioxidant concentrations (for example ascorbic acid)

() The authors 2014. Open Access under Creative Commons by Attribution Licence. Use, distribution and reproduction are unrestricted. Authors and original publication must be credited. 
are activated by plants to alleviate oxidative stress (Wójcik et al. 2006, Tewari et al. 2008, Wang et al. 2009). Zn stress can also induce the generation of nitric oxide (NO), an important stress-response hormone (Bartha et al. 2005, J. Xu et al. 2010). A recent report showed that NO was associated with longterm $\mathrm{Zn}$ tolerance in Solanum nigrum (J. Xu et al. 2010).

NO is a short-lived second messenger and acts as a diffusible free radical to readily react with a variety of intracellular and extracellular targets (Neill et al. 2003). It can be produced from $\mathrm{NO}_{2}^{-}$nonenzymatically or catalyzed by nitrate reductase in plants, and is involved in regulating plant growth and development, such as photomorphogenesis, seed germination, de-etiolation, hypocotyl elongation, organ maturation and senescence (Leshem et al. 1998). In addition, NO also participates in many processes as an antioxidant or anti-stress agent in response to abiotic stresses and has roles in the regulation of nutrient metabolism (Singh et al. 2008, Xiong et al. 2010). NO can also be released into waters by nitrifiers and denitrifiers in the aquatic environment, particularly at low $\mathrm{O}_{2}$ concentrations (Neill et al. 2003).

Submerged macrophytes play an important role in maintaining the health of aquatic ecosystems. The submerged sections of macrophytes growing under the water surface have adaptive mechanisms that differ from those of terrestrial plants. For example, their leaves can directly take up nutrients from the water, especially in water polluted with heavy metals. Consequently, submerged macrophytes are better adapted to absorbing heavy metals from water if they can thrive in those conditions (Wang et al. 2009). Although abundant data have shown that NO can improve the stress resistance in many terrestrial plants (Xiong et al. 2010), the role of NO in submerged macrophytes remains unclear.

Here we conducted a 2-stage experiment to study the role of $\mathrm{NO}$ in regulating the adaptation of submerged macrophytes to Zn stress using Hydrilla verticillata as a plant model. Sodium nitroprusside (SNP; a widely used NO donor) was used as the NO source, and the metabolic products of SNP were used as comparisons to confirm the effects of NO (Singh et al. 2008, 2009, Mostofa et al. 2014). The resultant changes in the levels of Zn and several other nutrient elements, the concentration of photosynthetic pigments and malondialdehyde, and the antioxidant response were assayed in leaves of $H$. verticillata treated with high levels of $\mathrm{Zn}$ alone or together with NO.

\section{MATERIALS AND METHODS}

\section{Materials and treatments}

Hydrilla verticillata plants were purchased from an aquaculture company in Hangzhou, China. The tips $(8 \mathrm{~cm})$ of plant offspring were cultured in $10 \%$ Hoagland solution in $70 \mathrm{l}$ plastic containers for $2 \mathrm{wk}$ under laboratory conditions. SNP (Sigma Chemical) solution, used as an exogenous NO donor, was freshly prepared. SNP metabolite solution consisted of $50 \mu \mathrm{M}$ sodium ferrocyanide, $50 \mu \mathrm{M}$ sodium nitrite and $50 \mu \mathrm{M}$ sodium nitrate. Fifty plantlets of similar growth stage were planted in 1 replicate for each treatment, and 4 replicates were used for each treatment (60 containers were used in total).

In the first stage, seedlings rooted in quartz sand were cultured (Days 1 to 4 ) in the following 5 solutions: (1) primary culture solution (control, 10\% Hoagland solution); (2) primary culture solution containing $10 \mathrm{mg} \mathrm{l}^{-1} \mathrm{Zn}$ (Z10); (3) primary culture solution containing $25 \mu \mathrm{M}$ SNP and $10 \mathrm{mg} \mathrm{l}^{-1} \mathrm{Zn}$ (ZS25); (4) primary culture solution containing $50 \mu \mathrm{M}$ SNP and $10 \mathrm{mg} \mathrm{l}^{-1} \mathrm{Zn}$ (ZS50); (5) primary culture solution containing $50 \mu \mathrm{M}$ SNP metabolite and $10 \mathrm{mg} \mathrm{l}^{-1} \mathrm{Zn}$ (ZS50M). In the second stage (Days 5 to 14), plants having received treatments of Z10, ZS25, ZS50 and ZS50M were further cultured in $10 \%$ Hoagland solution containing $10 \mathrm{mg} \mathrm{l}^{-1} \mathrm{Zn}$ for $10 \mathrm{~d}$; and for the control, in $10 \%$ Hoagland solution.

Throughout the acclimation and treatment periods, plants were cultured with a photoperiod of 12:12 h (light:dark) at a temperature of $24 \pm 0.1^{\circ} \mathrm{C}$ and an irradiance of $120 \mu \mathrm{E} \mathrm{m} \mathrm{m}^{2} \mathrm{~s}^{-1}$ under laboratory conditions. The culture solutions were renewed every $2 \mathrm{~d}$. All of the plants (5 $\mathrm{cm}$ of the tip portion) harvested from 1 container were considered as 1 sample. Harvested material was rinsed with distilled water, blotted, and immediately frozen in liquid nitrogen.

\section{Relative growth rate and mineral nutrient element content}

The fresh weight of the plants was recorded before (W1, Day 0) and after treatment (W2, Day 14). The relative growth rate (RGR) was calculated based on the formula: $100 \% \times(\mathrm{W} 2-\mathrm{W} 1) / \mathrm{W} 2$.

The harvested leaf samples were immediately washed with $50 \mu \mathrm{M}$ EDTA solution and doubledistilled water $\left(\mathrm{ddH}_{2} \mathrm{O}\right)$ in sequence. The washed material was incubated in a forced-draught oven at $105^{\circ} \mathrm{C}$ for $20 \mathrm{~min}$ and then dried at $80^{\circ} \mathrm{C}$ for $24 \mathrm{~h}$. A 
$0.1 \mathrm{mg}$ aliquot of the dried sample was powdered and digested in 10:1 $\mathrm{HNO}_{3}: \mathrm{HClO}_{4}$ solution and heated at $150-200^{\circ} \mathrm{C}$ until near dryness. The cooled residue was dissolved in $5 \mathrm{ml}$ of $5 \% \mathrm{HNO}_{3}$, and $\mathrm{ddH}_{2} \mathrm{O}$ was added to make $15 \mathrm{ml}$ of total volume. The concentrations of $\mathrm{Zn}, \mathrm{Cu}, \mathrm{Fe}, \mathrm{Mn}$ and $\mathrm{Na}$ were determined using inductively-coupled plasma atomic emission (Prodigy, Leeman-LABS).

\section{Determination of photosynthetic pigments and metabolite}

Concentrations of chlorophyll (chl) $(a+b)$ and carotenoids were measured as described by Lichtenthaler \& Wellburn (1983) after extraction with 80\% acetone. Content of malondialdehyde (MDA), NO and non-protein thiols (NP-SH) was determined based on the methods described previously (Wang et al. 2011).

\section{Assay of antioxidant enzymes}

To assay the catalytic activities of various enzymes, $1 \mathrm{~g}$ of powdered sample was homogenized in $5 \mathrm{ml}$ of $50 \mathrm{mM}$ potassium phosphate buffer ( $\mathrm{pH}$ 7.0) containing $1 \mathrm{mM}$ EDTA, $2 \mathrm{mM} \mathrm{MgCl}_{2}$, and $1 \%$ polyvinylpyrrolidone. For the APX assay, $1 \mathrm{mM}$ ascorbic acid (AsA) was included in the same reaction as above. The homogenate was centrifuged at $12000 \times g$ (20 min at $4^{\circ} \mathrm{C}$ ), and the supernatant was used for the enzyme assays. The protein content was determined by the method of Bradford (1976) using bovine serum albumin as a standard.

SOD activity was assayed according to the method described by Beauchamp \& Fridovich (1971). One unit of SOD activity was defined as the amount of enzyme required to cause a $50 \%$ inhibition of the rate of nitroblue tetrazolium (NBT) as monitored spectrophotometrically at $560 \mathrm{~nm}$. CAT activity was determined by measuring the change of absorbance at $240 \mathrm{~nm}$ that accompanied the consumption of $\mathrm{H}_{2} \mathrm{O}_{2}$ (Aebi 1974). One unit of CAT activity $(\varepsilon=$

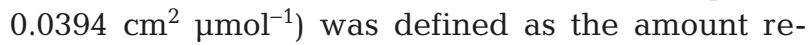
quired to decompose $1 \mathrm{nmol} \mathrm{H}_{2} \mathrm{O}_{2} \mathrm{~min}^{-1} \mathrm{mg}^{-1}$ protein.

POD activity was determined according to the method of Upadhyaya et al. (1985). One unit of POD ( $\varepsilon=26.6 \mathrm{mM}^{-1} \mathrm{~cm}^{-1}$ ) activity was defined as the amount required to convert $1 \mu \mathrm{mol}$ guaiacol $\mathrm{min}^{-1} \mathrm{~g}^{-1}$ fresh weight. Glutathione reductase (GR) activity was assayed by following the reduction of NADPH reflected as a change of the absorbance at $340 \mathrm{~nm}$ as described by Carlberg \& Mannervik (1985), and activity was calculated using the extinction coefficient $\varepsilon=6.22 \mathrm{mM}^{-1} \mathrm{~cm}^{-1}$. One unit of GR activity was defined as the amount required to decompose $1 \mathrm{nmol}$ NADPH min $^{-1} \mathrm{mg}^{-1}$ protein. APX activity was determined essentially as described by Nakano \& Asada (1981). One unit of APX activity $\left(\varepsilon=2.8 \mathrm{mM}^{-1} \mathrm{~cm}^{-1}\right)$ was defined as the amount required to decompose $1 \mu \mathrm{mol}$ AsA oxidized $\mathrm{min}^{-1} \mathrm{mg}^{-1}$ protein.

\section{Statistical analyses}

Each value shown in the figures and tables is mean \pm SE of 4 replicates $(n=4)$. All data were analyzed by 1-way ANOVA and Tukey's test, and significance was considered at $\mathrm{p}<0.05$. All statistical analyses were performed with SPSS software (version 19.0).

\section{RESULTS}

Compared to the control, plant Zn concentrations increased significantly in all treatments on Days 1 and 4 (Table 1). However, the addition of SNP significantly inhibited the uptake of Zn on Day 4 (Table 1). A significant increase in plant $\mathrm{Cu}$ concentration was detected in ZS50 on Day 4 (Table 1). Plant Fe concentration increased significantly when exposed to ZS50 on Day 1; and by Day 4, it increased by 71, 135, 210 and $98 \%$, respectively, in treatments Z10, ZS25, ZS50 and ZS50M, as compared to the control (Table 1). A significant increase in plant $\mathrm{Mn}$ was recorded in Z10, ZS25, ZS50 and ZS50M on Days 1 and 4, while plant Mn concentration was obviously lower in ZS25 and ZS50 than ZS50M (Table 1). In ZS25 and ZS50, plant Na concentration evidently decreased on Day 1, this was significant only on Day 4 (Table 1).

At the second stage, no significant alteration was observed among the treatments Z10, ZS25, ZS50, and ZS50M on Day 14. Plant Cu concentration was higher in ZS25 and ZS50 than in the other treatments, while the highest value in plant Fe was detected in ZS25. Plant Mn concentration was higher by $43.46 \%, 13.12 \%, 35.25 \%$, and $35.48 \%$, respectively, in ZS25, ZS50 and ZS50M, compared to the control. However, plant $\mathrm{Na}$ concentration was lower in ZS25 and ZS50. The RGR was higher in the control than all other treatments containing high $\mathrm{Zn}$ on Day 14, but the RGR was higher in ZS25 and ZS50 than Z10 and ZS50M.

NO increased significantly in plants of ZS25, ZS50 and ZS50M on Day 1 and in Z10, ZS25, ZS50 and 
Table 1. Effects of sodium nitroprusside (SNP) on nutrient concentration ( $\mathrm{mg} \mathrm{kg}^{-1}$ dry weight) in leaves of Hydrilla verticillata. From Days 5 to 14, the culture solution consisted of $10 \mathrm{mg} \mathrm{l}^{-1} \mathrm{Zn}$ only in all 4 treatment groups (except for the control). Different superscripts indicate significant differences at $\mathrm{p}<0.05(\mathrm{n}=4$; Tukey's test). The relative growth rate (RGR) was the increase in fresh weight after the treatment

\begin{tabular}{|c|c|c|c|c|c|c|}
\hline Day & & Control & $\begin{array}{c}\mathrm{Z10} \\
\left(10 \mathrm{mg} \mathrm{l}^{-1} \mathrm{Zn}\right)\end{array}$ & $\begin{array}{c}\text { ZS25 } \\
(25 \mu M \text { SNP + } \\
\left.10 \mathrm{mg} \mathrm{l}^{-1} \mathrm{Zn}\right)\end{array}$ & $\begin{array}{c}\text { ZS50 } \\
(50 \mu M \text { SNP + } \\
\left.10 \mathrm{mg} \mathrm{l}^{-1} \mathrm{Zn}\right)\end{array}$ & 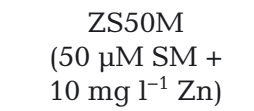 \\
\hline 1 & $\begin{array}{l}\mathrm{Zn} \\
\mathrm{Cu} \\
\mathrm{Fe} \\
\mathrm{Mn} \\
\mathrm{Na}\end{array}$ & $\begin{aligned} 37.57 & \pm 4.96^{\mathrm{c}} \\
22.50 & \pm 2.15^{\mathrm{a}} \\
634.22 & \pm 43.42^{\mathrm{b}} \\
28.92 & \pm 1.89^{\mathrm{ab}} \\
89.69 & \pm 6.87^{\mathrm{a}}\end{aligned}$ & $\begin{aligned} 4468.25 & \pm 428.14^{\mathrm{b}} \\
24.20 & \pm 6.48^{\mathrm{a}} \\
618.20 & \pm 48.01^{\mathrm{b}} \\
45.30 & \pm 5.51^{\mathrm{a}} \\
80.09 & \pm 5.55^{\mathrm{ab}}\end{aligned}$ & $\begin{aligned} 5869.02 & \pm 103.70^{\mathrm{a}} \\
21.11 & \pm 2.46^{\mathrm{a}} \\
652.21 & \pm 81.40^{\mathrm{b}} \\
41.36 & \pm 6.58^{\mathrm{ab}} \\
67.78 & \pm 0.76^{\mathrm{b}}\end{aligned}$ & $\begin{aligned} 5029.48 & \pm 912.63^{\mathrm{ab}} \\
16.01 & \pm 3.25^{\mathrm{a}} \\
872.83 & \pm 80.08^{\mathrm{a}} \\
36.84 & \pm 4.89^{\mathrm{ab}} \\
63.81 & \pm 2.14^{\mathrm{b}}\end{aligned}$ & $\begin{aligned} 4804.72 & \pm 86.41^{\mathrm{ab}} \\
17.91 & \pm 1.01^{\mathrm{a}} \\
581.66 & \pm 57.39^{\mathrm{b}} \\
39.14 & \pm 1.96^{\mathrm{b}} \\
79.48 & \pm 10.74^{\mathrm{ab}}\end{aligned}$ \\
\hline 4 & $\begin{array}{l}\mathrm{Zn} \\
\mathrm{Cu} \\
\mathrm{Fe} \\
\mathrm{Mn} \\
\mathrm{Na}\end{array}$ & $\begin{aligned} 34.66 & \pm 0.73^{\mathrm{d}} \\
15.81 & \pm 1.82^{\mathrm{c}} \\
291.43 & \pm 17.41^{\mathrm{d}} \\
23.30 & \pm 4.71^{\mathrm{c}} \\
82.95 & \pm 1.53^{\mathrm{b}}\end{aligned}$ & $\begin{aligned} 16267.40 & \pm 301.4^{\mathrm{b}} \\
19.25 & \pm 1.08^{\mathrm{bc}} \\
327.76 & \pm 24.7^{\mathrm{c}} \\
44.73 & \pm 8.72^{\mathrm{a}} \\
94.30 & \pm 4.52^{\mathrm{a}}\end{aligned}$ & $\begin{aligned} 11233.41 & \pm 924^{\mathrm{c}} \\
20.78 & \pm 2.03^{\mathrm{ab}} \\
450.53 & \pm 64.37^{\mathrm{b}} \\
27.84 & \pm 4.42^{\mathrm{c}} \\
61.15 & \pm 4.33^{\mathrm{c}}\end{aligned}$ & $\begin{aligned} 12401.75 & \pm 479^{\mathrm{c}} \\
23.78 & \pm 1.79^{\mathrm{a}} \\
594.13 & \pm 70.81^{\mathrm{a}} \\
34.68 & \pm 6.41^{\mathrm{ab}} \\
62.66 & \pm 5.21^{\mathrm{c}}\end{aligned}$ & $\begin{aligned} 16788.63 & \pm 1011^{\mathrm{a}} \\
17.09 & \pm 1.75^{\mathrm{bc}} \\
380.26 & \pm 25.69^{\mathrm{bc}} \\
47.17 & \pm 6.15^{\mathrm{a}} \\
75.77 & \pm 6.22^{\mathrm{b}}\end{aligned}$ \\
\hline 14 & $\begin{array}{l}\mathrm{Zn} \\
\mathrm{Cu} \\
\mathrm{Fe} \\
\mathrm{Mn} \\
\mathrm{Na}\end{array}$ & $\begin{aligned} 39.64 & \pm 1.78^{\mathrm{b}} \\
16.34 & \pm 1.23^{\mathrm{b}} \\
392.65 & \pm 35.27^{\mathrm{b}} \\
26.12 & \pm 3.44^{\mathrm{c}} \\
77.47 & \pm 4.54^{\mathrm{ab}}\end{aligned}$ & $\begin{aligned} 16947.17 & \pm 301^{\mathrm{a}} \\
18.94 & \pm 1.23^{\mathrm{b}} \\
529.46 & \pm 24.7^{\mathrm{b}} \\
37.73 & \pm 5.94^{\mathrm{a}} \\
82.62 & \pm 6.43^{\mathrm{a}}\end{aligned}$ & $\begin{aligned} 16543.82 & \pm 1357^{\mathrm{a}} \\
21.59 & \pm 2.53^{\mathrm{a}} \\
499.54 & \pm 54.39^{\mathrm{b}} \\
29.75 & \pm 3.81^{\mathrm{bc}} \\
65.32 & \pm 5.92^{\mathrm{b}}\end{aligned}$ & $\begin{aligned} 15974.21 & \pm 953^{\mathrm{a}} \\
24.21 & \pm 1.55^{\mathrm{a}} \\
602.53 & \pm 44.46^{\mathrm{a}} \\
35.57 & \pm 4.34^{\mathrm{ab}} \\
67.92 & \pm 4.73^{\mathrm{b}}\end{aligned}$ & $\begin{aligned} 16523.32 & \pm 842^{\mathrm{a}} \\
18.42 & \pm 1.64^{\mathrm{b}} \\
470.35 & \pm 42.93^{\mathrm{b}} \\
35.63 & \pm 5.66^{\mathrm{ab}} \\
73.43 & \pm 5.98^{\mathrm{ab}}\end{aligned}$ \\
\hline RGR (\%) & & $34.39 \pm 5.97^{a}$ & $6.61 \pm 1.92^{\mathrm{c}}$ & $12.95 \pm 2.72^{b}$ & $14.77 \pm 5.28^{\mathrm{b}}$ & $7.33 \pm 3.71^{\mathrm{c}}$ \\
\hline
\end{tabular}
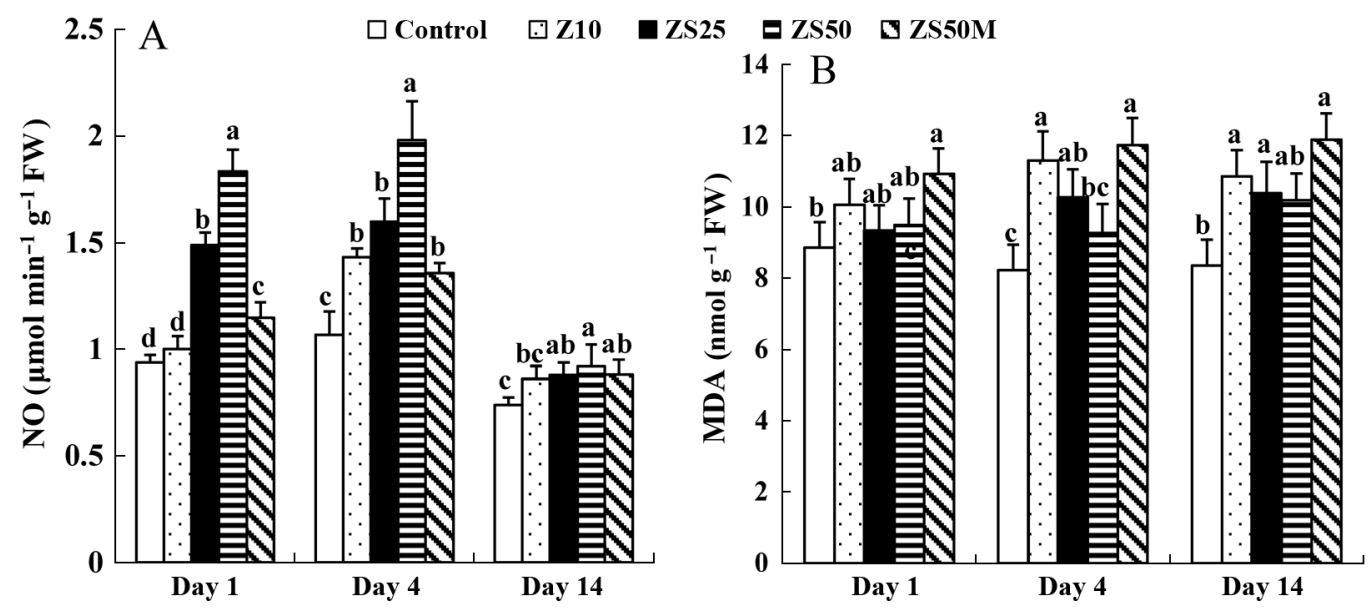

Fig. 1. Effect of SNP on levels of (A) nitric oxide (NO) and (B) malondialdehyde (MDA) contents in leaves of Hydrilla verticillata under Zn stress. Different lowercase letters indicate significant differences at $\mathrm{p}<0.05$ (Tukey's test). FW $=$ fresh weight

ZS50M on Day 4, as compared to the control (Fig. 1A). The maximum NO concentration was detected in ZS50 on Days 1 and 4. Compared to the control, MDA concentration increased significantly in plants exposed to ZS50M on Day 1 and on Day 4, and was higher in Z10, ZS25 and ZS50M than in the control and ZS50 (Fig. 1B). The concentrations of NO and MDA were lower in the control than other treatments on Day 14.

$\mathrm{Chl}(a+b)$ content decreased significantly in ZS25 or ZS50M on Day 1 and in all treatments on Day 4, as compared to the control (Fig. 2A). In addition, chl $(a+b)$ content was higher in ZS50 than ZS10 or ZS50M. No significant alteration was observed in plant carotenoid concentrations in all the treatments on Day 1, while carotenoid concentrations decreased in ZS10 and ZS25 on Day 4 (Fig. 2B). NP-SH concentration changed normally in Z10, ZS25 and ZS50M but significantly increased in ZS50M on Day 1 ; by Day 4, NP-SH increased in Z10 (21.7\%), ZS25 (46.5\%), ZS50 (32.7\%) and ZS50M (29.1\%; Fig. 2C). SOD activity increased significantly in ZS25 and ZS50 on Day 1 and in Z10, ZS25, ZS50 and ZS50M on Day 4 (Fig. 2D). 


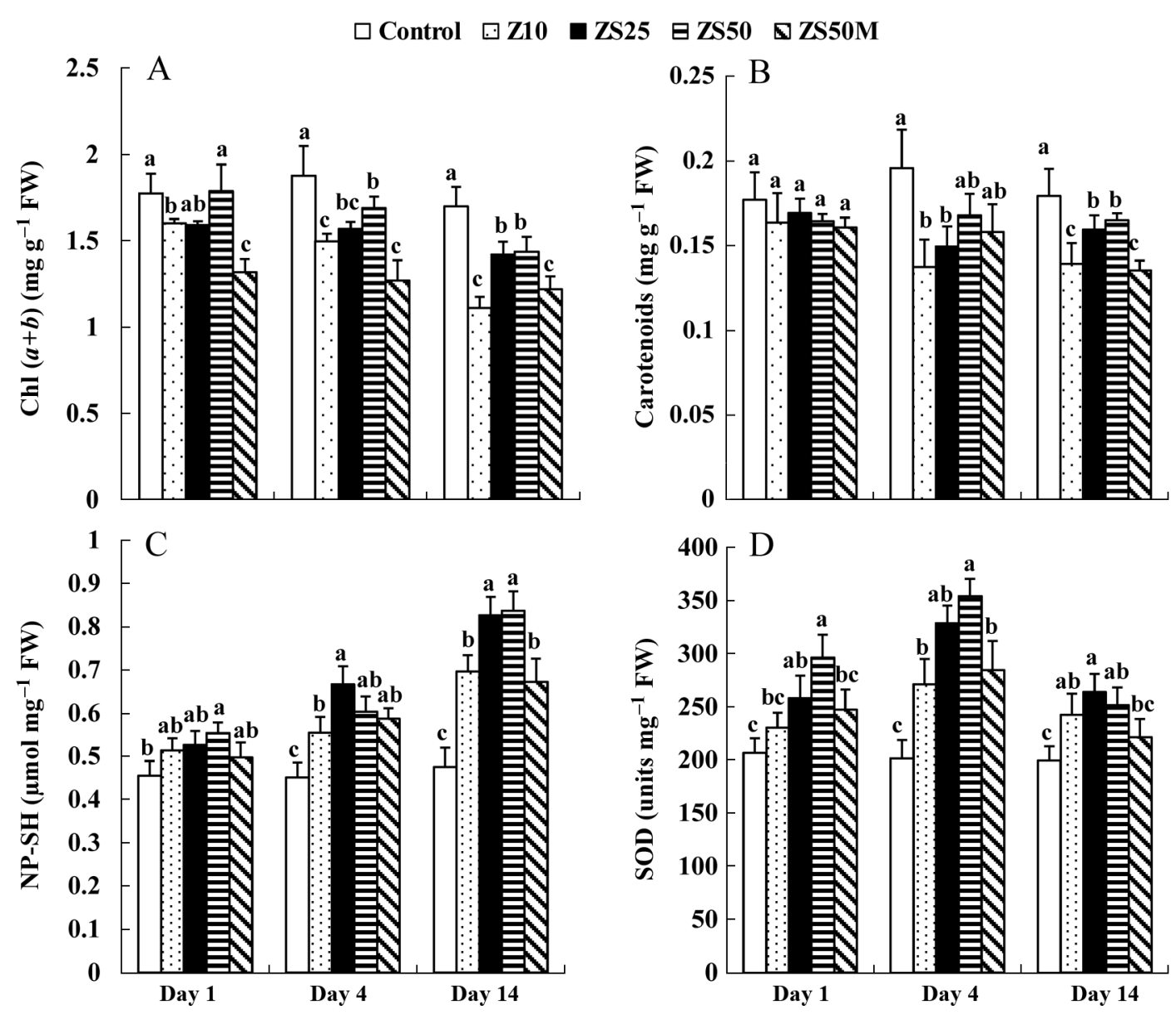

Fig. 2. Effect of SNP on the concentrations of (A) chlorophyll $(a+b)$, (B) carotenoids, (C) non-protein thiols (NP-SH), and (D) superoxide dismutase (SOD) in leaves of Hydrilla verticillata exposed to Zn stress. Different lowercase letters indicate significant differences at $\mathrm{p}<0.05$ (Tukey's test)

In the second stage (Day 14), values of chl $(a+b)$, carotenoid, and NP-SH contents, and SOD activity were higher in ZS25 and ZS50 than in Z10 and ZS50M. Chl $(a+b)$ and carotenoid contents decreased, but NP-SH content and SOD activity increased in Z10, ZS25, ZS50 and ZS50M, as compared to the control. Meanwhile, chlorosis was observed in plant leaves of Z10 and ZS50M, while no significant symptoms were observed in plant leaves of ZS25 and ZS50.

Compared to the control, CAT increased by 34.4, 91.8, 47.6 and $14.1 \%$, respectively, in Z10, ZS2, ZS50, and ZS50M on Day 1 and by 26.1, 56.4, 131.8 and $84.0 \%$, respectively, on Day 4 (Fig. 3A). POD decreased by $25.9,14.4,16.8$ and $28.4 \%$ of control values, respectively, in plants exposed to Z10, ZS25, ZS50 and ZS50M on Day 1; and by 32.3, 58.3, 81.8 and $34.4 \%$ on Day 4 , respectively (Fig. 3B). The highest value of APX activity was recorded in ZS25 on Day 1 ; by Day 4, increases by 28.6, 45.2, 82.5 and
$36.6 \%$ of control values were respectively detected in Z10, ZS25, ZS50 and ZS50M (Fig. 3C). GR activity decreased by 29.3 and $6.1 \%$, respectively, in Z10 and ZS50M, while it increased by 35.3 and $54 \%$, respectively, in ZS25 and ZS50 on Day 1, as compared to the control (Fig. 3D). The lowest and the highest values of GR activity were respectively detected in Z10 and ZS50 on Day 4. In the second stage (14 d), CAT, POD, APX and GR activities were higher in ZS25 and ZS50 than in Z10 and ZS50M.

Plant AsA content increased by 9.6, 33.2, 17.9 and $4.8 \%$ of control values, respectively, in Z10, ZS25, ZS50 and ZS50M on Day 1; and by 5.9, 23.9, 32.1 and $9.8 \%$ on Day 4, respectively (Fig. 4A). As compared to controls, plant docosahexaenoic acid (DHA) content changed normally in all the treatments on Day 1 but significantly changed on Day 4 . SNP application decreased the DHA concentration in plants exposed to ZS25 and ZS50, as compared with ZS50M (Fig. 4B). In the second stage, AsA con- 


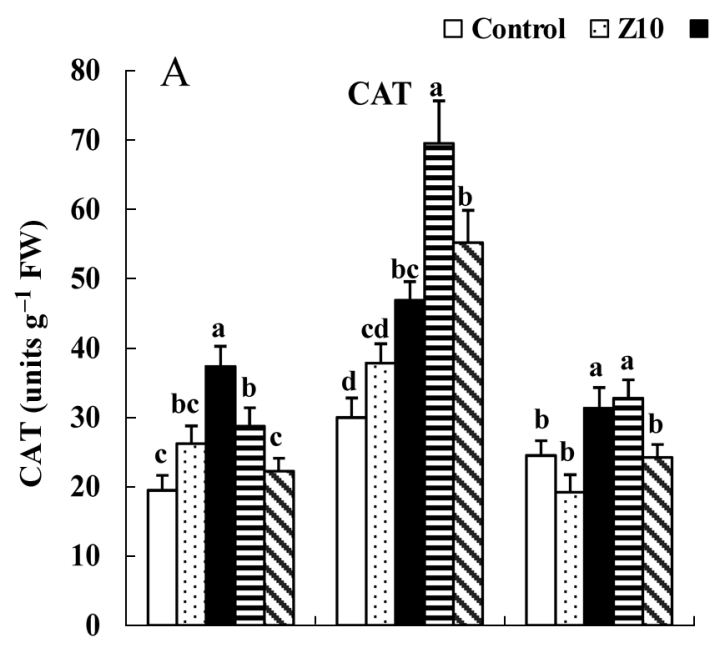

ZS25 曰ZS50 $\triangle$ ZS50M
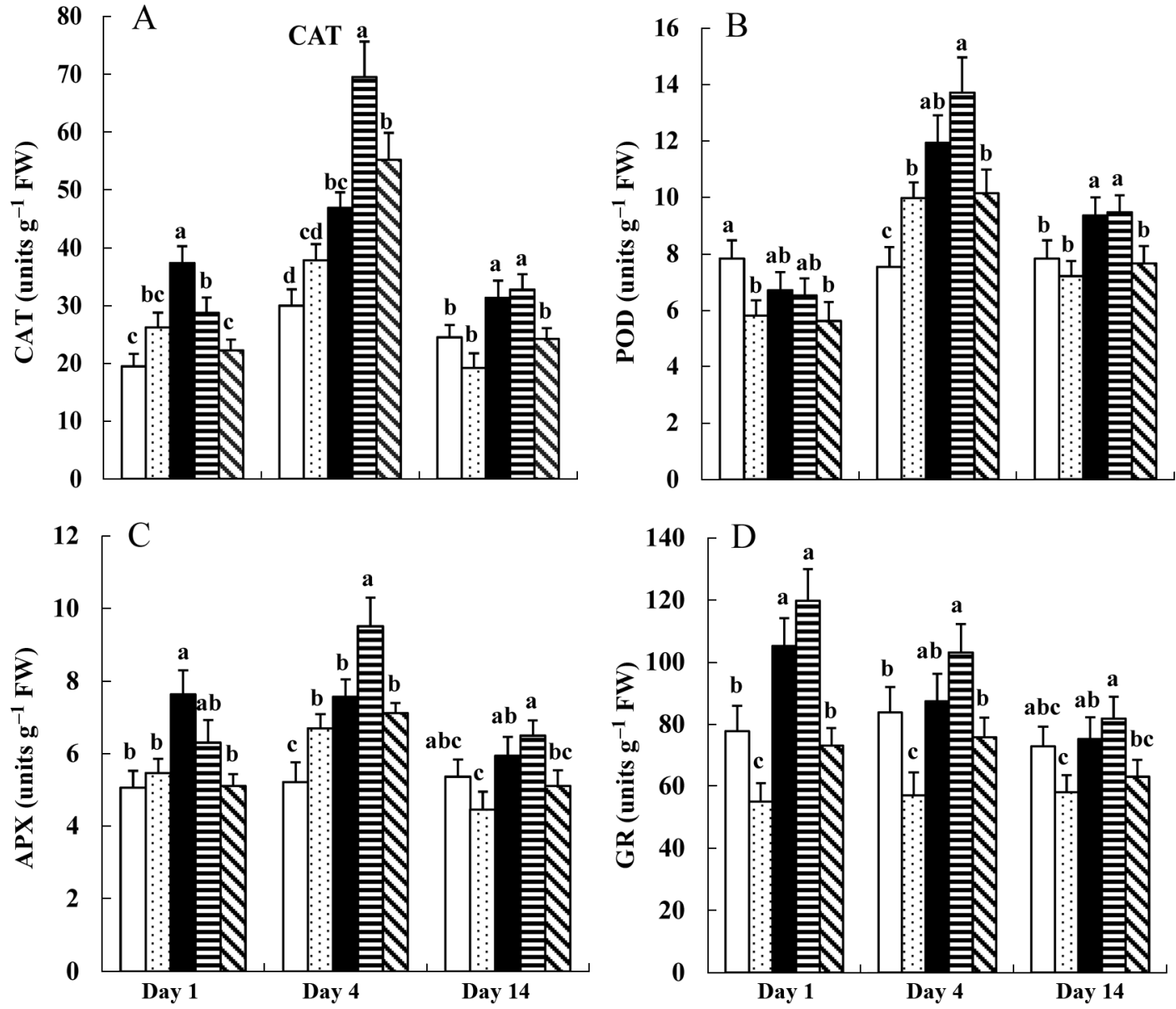

Fig. 3. Effect of SNP on the activities of (A) catalase (CAT), (B) guaiacol peroxidase (POD), (C) ascorbate peroxidase (APX), and (D) glutathione reductase (GR) of Hydrilla verticillata. Different lowercase letters indicate significant differences at $\mathrm{p}<0.05$ (Tukey's test)

tent was obviously lower in controls than in ZS25 and ZS50 but was higher than in Z10 and ZS50M; however, DHA content was higher in controls than in other treatments.

\section{DISCUSSION}

In aquatic environments, heavy metals can accumulate in aquatic macrophytes, inducing a variety of cellular changes which may directly contribute to the metal tolerance capacity of plants ((Singh et al. 2008, Q. Xu et al. 2010). NO, a type of hormone, is important for plants to cope with various stresses. However, Hydrilla verticillata can be damaged when exposed to high levels of NO (e.g. a long time of exposure to NO; Wang et al. 2010). In addition, in our experiment, NO was initially released quickly because SNP degrades quickly in the medium. There- fore, we replaced the solution every $2 \mathrm{~d}$ in the first stage of this experiment to reduce the potential toxic effects of NO. The increase of NO in ZS25 and ZS50 should be ascribed to the breakdown of SNP. However, an increase in $\mathrm{NO}$ was detected in $H$. verticillata plants exposed to $\mathrm{Zn}$ on Day 4, suggesting that excess $\mathrm{Zn}$ induced the generation of NO. High Zninduced NO was also found in the terrestrial plants Brassica juncea, Pisum sativum, and Solanum nigrum (Bartha et al. 2005, J. Xu et al. 2010). Increased NO concentration may be produced by peroxisomes and mitochondria and by the activity of nitrate reductase in plant cells (Xiong et al. 2010).

It is interesting to note that NO stimulated the uptake of $\mathrm{Zn}$ in leaves of $H$. verticillata on Day 1, but on Day 4, an inhibition effect on $\mathrm{Zn}$ accumulation was detected (Table 1). Zn uptake is associated with metallothionein proteins, which are the critical targets of NO (Desbrosses-Fonrouge et al. 2005, Arri- 

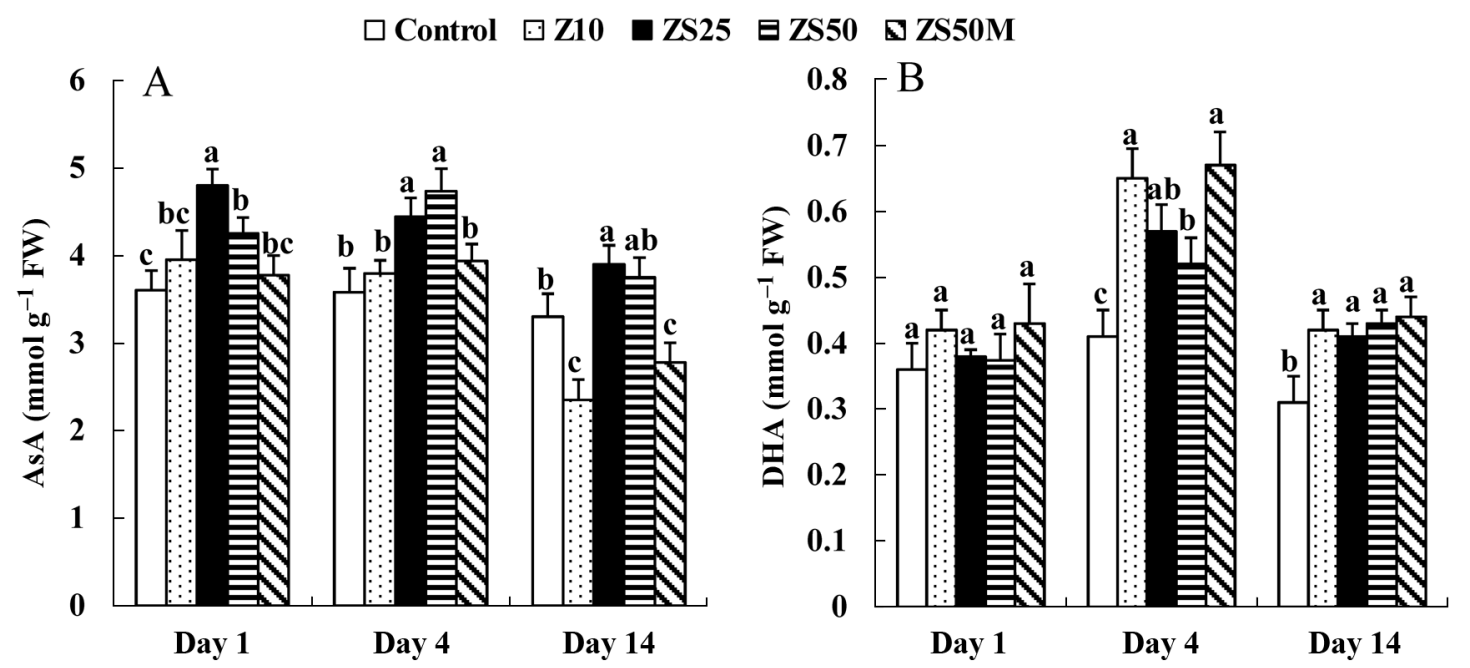

Fig. 4. Effect of SNP on the contents of (A) ascorbic acid (AsA) and (B) docosahexaenoic acid (DHA) of Hydrilla verticillata exposed to Zn. Different lowercase letters indicate significant differences at $p<0.05$ (Tukey's test)

vault et al. 2006, Stitt et al. 2006, Aguilar-Alonso et al. 2008). Our data supported the viewpoint that NO is involved in maintaining a suitable $\mathrm{Zn}$ concentration and alleviating the adverse effect of excess $\mathrm{Zn}$ induced toxicity (Abdel-kader 2007).

Metals like $\mathrm{Cu}, \mathrm{Fe}, \mathrm{Mn}$ and $\mathrm{Na}$ are important for plants. Plant $\mathrm{Cu}$ varied normally among the treatments on Day 1 (Table 1). Exogenous NO supply did not affect $\mathrm{Cu}$ uptake in roots of Panax ginseng on Day 1 (Tewari et al. 2008). However, plant $\mathrm{Cu}$ increased in ZS50 as compared with ZS50M and Z10 on Day 4 (Table 1). The increase of plant Fe content induced by NO (Table 1) might be attributed to the expression of Fe uptake-related genes, which could be induced by NO (Besson-Bard et al. 2009). A recent report by J. Xu et al. (2010) showed that NO was required for metal (especially $\mathrm{Fe}$ ) uptake and homeostasis in plants exposed to excess Zn. Kumar et al. (2010) suggested that by means of modulating the redox, NO application could increase the intracellular availability of Fe.

Mn participates in both oxygen radical production in PSII and in the oxygen radical detoxification in mitochondria (Shenker et al. 2004). NO application inhibited $\mathrm{Mn}$ uptake in $H$. verticillata plants under Zn stress (Table 1). Na always causes osmotic stress for plants, thought it can substitute for $\mathrm{K}$ in some circumstances. NO application decreased $\mathrm{Na}$ content (Table 1). A decrease in Na content by NO in maize seedlings under $\mathrm{NaCl}$ stress was also reported by Zhang et al. (2006), who suggested that NO might regulate the activities of vacuolar $\mathrm{H}^{+}$-ATPase and $\mathrm{H}^{+}$PPase.
SNP application inhibited Zn-induced alteration in MDA (Fig. 1B) and chl $(a+b)$ content (Fig. 2A) in leaves of $H$. verticillata. These results might be attributed to the enhancement of antioxidant responses (Neill et al. 2003, Shi et al. 2007, Xiong et al. 2010) and the improvement of nutrient composition (Wang et al. 2009). Meanwhile, SNP application induced a slight increase in carotenoid content (Fig. 2B) in $H$. verticillata, as compared to ZS50M. Kumar et al. (2010) showed that SNP application significantly increased the carotenoid content in maize. An increase in carotenoids may alleviate the damage from oxidative stress in chloroplasts, since carotenoids play a vital role in the photosynthetic reaction center of photosynthetic organisms.

The $25 \mu \mathrm{M}$ SNP application increased the NP$\mathrm{SH}$ content in leaves of $H$. verticillata on Day 4 (Fig. 2C). Similar results were found in the roots of $P$. ginseng (Tewari et al. 2008), while Kumar et al. (2010) showed a reduction in NP-SH content in maize plants exposed to SNP. NP-SH is a thiol pool containing monothiols (e.g. cysteine and reduced glutathione) and phytochelatins and has important roles in reducing heavy metal toxicity (Powell 2000). Thus, the effect of NO was likely a result of the adjustment of total or free SH levels (Abdel-kader 2007).

Efficient antioxidant mechanisms are crucial for cells to cope with excess ROS. In this study, NO application stimulated the activities of antioxidant enzymes including SOD, CAT and POD (Figs. 2B \& $3 \mathrm{~A}, \mathrm{~B})$, suggesting that $\mathrm{NO}$ application enhanced the antioxidant response in $H$. verticillata to resist oxidative stress. Shi et al. (2007) found that SOD activity 
was regulated by $\mathrm{NO}$ in plants under $\mathrm{NaCl}$ stress on Day 4. The NO-induced increase in POD activity might contribute to the polymerization of phenoxy compounds to produce components such as lignins that stiffen cell walls (Reddy et al. 2005). APX and GR are 2 main enzymes of the ascorbate-glutathione cycle, which are localized mainly in chloroplasts and play an important role in combating oxidative stress (Shigeoka et al. 2002). APX and GR activity was induced by $\mathrm{NO}$ in $H$. verticillata plants under $\mathrm{Zn}$ stress (Fig. 3C,D). The increased antioxidant enzyme activity might be ascribed to the role of NO in stimulating the expression of their genes (Besson-Bard et al. 2009, Xiong et al. 2010). Recently, many NOinduced stress resistance genes were screened in different plants by a genomic microarray (Besson-Bard et al. 2009). AsA is the major redox regulatory antioxidant and is able to detoxify ROS by direct scavenging or by acting as a substrate in the ascorbateglutathione cycle (Apel \& Hirt 2004). AsA content increased in treatments with NO (Fig. 4A), suggesting that the exogenous NO supply enhanced the tolerance against Zn-induced oxidative stress in $H$. verticillata.

To study the effects of NO application on the adaptation of $H$. verticillata under Zn stress, after $4 \mathrm{~d}$ of treatments, plants of Z10, ZS25, ZS50 and ZS50M were further treated with $10 \mathrm{mg} \mathrm{l}^{-1} \mathrm{Zn}^{2+}$ for $10 \mathrm{~d}$ (until Day 14). $\mathrm{Zn}, \mathrm{Cu}, \mathrm{Fe}, \mathrm{Mn}$ and $\mathrm{Na}$ contents were altered by $\mathrm{NO}$ in different patterns in leaves of $H$. verticillata plants under Zn stress, providing the evidence that NO is involved in the regulation of nutrient element uptake in plants under Zn stress. The disturbed nutrient uptake may be ascribed to the roles of NO in regulating metal uptake/transporterrelated gene expression and/or protein activity (Besson-Bard et al. 2009). NO obviously decreased in the treatments of ZS25 and ZS50 on Day 4, as compared to Day 14, demonstrating that exogenous NO decreased after the removal of SNP. Meanwhile, $\mathrm{Cu}$, Fe and Mn contents increased in treatments ZS25 and ZS50 on Day 14 as compared to Day 4. The improved growth traits in $H$. verticillata by NO application in this study might be associated with the altered nutrient element content.

No significant alterations in $\mathrm{Zn}$ content were observed among the treatments on Day 14. However, the RGR was higher in ZS25 and Z50 than in Z10 and ZS50M. These results indicate that pretreatment with NO could increase biomass production under Zn stress. The increased biomass production might be associated with the increase in photosynthetic pigment content and the alleviated damage, which can be revealed by the decreased MDA content and increased antioxidant response on Day 14.

In conclusion, exogenous NO partially reversed Zn-induced reduction of photosynthetic pigments and the increase of MDA content. NO application improved the nutrient balance and antioxidant ability in response to $\mathrm{Zn}$ stress. The effects of $\mathrm{NO}$ on these parameters may contribute to the accumulation of biomass. Consequently, pretreatment with NO may be a useful way to improve the effects of ecological remediation and phytoremediation of Zn-polluted waters.

Acknowledgements. This study was in part supported by grants from the National Natural Science of China (No. 51379063 and State Key Program No. 41430751); the Outstanding Youth Fund of Jiangsu Province (BK2012037), Jiangsu Provincial Natural Science Foundation (No. BK2012413) and the Research Fund for innovation team of the Ministry of Education (IRT13061).

\section{LITERATURE CITED}

Abdel-kader DZE (2007) Role of nitric oxide glutathione and sulfhydryl groups in zinc homeostasis in plants. Am J Plant Physiol 2:59-75

Aebi H (1974) Catalase. In: Bergmeyer HU (ed) Methods of enzymatic analysis. Verlag Chemie, Weinheim, p 673-680

Aguilar-Alonso $\mathrm{P}$, Martinez-Fong $\mathrm{D}$, Pazos-Salazar NG, Brambila E and others (2008) The increase in zinc levels and upregulation of zinc transporters are mediated by nitric oxide in the cerebral cortex after transient ischemia in the rat. Brain Res 1200:89-98

Apel K, Hirt H (2004) Reactive oxygen species: metabolism, oxidative stress, and signaling transduction. Annu Rev Plant Biol 55:373-399

Arrivault S, Senger T, Kramer U (2006) The Arabidopsis metal tolerance protein AtMTP3 maintains metal homeostasis by mediating $\mathrm{Zn}$ exclusion from the shoot under Fe deficiency and Zn oversupply. Plant J 46:861-879

Bartha B, Kolbert Z, Erdei L (2005) Nitric oxide production induced by heavy metals in Brassica juncea L. Czern. and Pisum sativum L. Acta Biol Szeged 49:9-12

Beauchamp C, Fridovich I (1971) Superoxide dismutase: improved assays and an assay applicable to acrylamide gels. Anal Biochem 44:276-287

Besson-Bard A, Astier J, Rasul S, Wawer I, Dubreuil-Maurizi C, Jeandroz S, Wendehenne D (2009) Current view of nitric oxide-responsive genes in plants. Plant Sci 177: 302-309

> Beyersmann D, Haase H (2001) Functions of zinc in signaling proliferation and differentiation of mammalian cells. Biometals 14:331-341

Bradford MM (1976) A rapid and sensitive method for the quantitation of microgram quantities of protein utilizing the principle of protein-dye binding. Anal Biochem 72: 248-254

> Broadley MR, White PJ, Hammond JP, Zelko I, Lux A (2007) Zinc in plants. New Phytol 173:677-702

Carlberg C, Mannervik B (1985) Glutathione reductase 
assay. In: Meister A (ed) Methods in enzymology Vol 113. Academic Press, New York, NY p 488-495

Ciftci-Yilmaz S, Mittler R (2008) The zinc finger network of plants. Cell Mol Life Sci 65:1150-1160

> Desbrosses-Fonrouge AG, Voigt K, Schroder A, Arrivault S, Thomine S, Kramer U (2005) Arabidopsis thaliana MTP1 is a $\mathrm{Zn}$ transporter in the vacuolar membrane which mediates $\mathrm{Zn}$ detoxification and drives leaf $\mathrm{Zn}$ accumulation. FEBS Lett 579:4165-4174

Kumar P, Tewari RK, Sharma PN (2010) Sodium nitroprusside-mediated alleviation of iron deficiency and modulation of antioxidant responses in maize plants. AoB Plants 2010:plq002

Leshem YY, Willis RBH, Ku VV (1998) Evidence for the function of the free radical gas - nitric oxide (NO) - as an endogenous maturation and senescence regulating factor in higher plants. Plant Physiol Biochem 36:825-833

Lichtenthaler HK, Wellburn AR (1983) Determinations of total carotenoids and chlorophylls $a$ and $b$ of leaf extracts in different solvents. Biochem Soc Trans 11:591-592

Mostofa MG, Seraj ZI, Fujita M (2014) Exogenous sodium nitroprusside and glutathione alleviate copper toxicity by reducing copper uptake and oxidative damage in rice (Oryza sativa L.) seedlings. Protoplasma 251:1373-1386

Nakano Y, Asada K (1981) Hydrogen peroxide is scavenged by ascorbate-specific peroxidase in spinach chloroplast. Plant Cell Physiol 22:867-880

> Neill SJ, Desikan R, Hancock JT (2003) Nitric oxide signalling in plants. New Phytol 159:11-35

Powell SR (2000) The antioxidant properties of zinc. J Nutr 130 (5S Suppl):1447S-1454S

Reddy AM, Kumar SG, Jyothsnakumari G, Thimmanaik S, Sudhakar C (2005) Lead induced changes in antioxidant metabolism of horsegram (Macrotyloma uniflorum (Lam) Verdc) and bengalgram (Cicer arietinum L). Chemosphere 60:97-104

Rout GR, Das P (2003) Effect of metal toxicity on plant growth and metabolism: I. Zinc. Agronomie 23:3-11

Shenker M, Plessner OE, Tel-Or E (2004) Manganese nutrition effects on tomato growth, chlorophyll concentration, and superoxide dismutase activity. J Plant Physiol 161: 197-202

Shi Q, Ding F, Wang X, Wei M (2007) Exogenous nitric oxide protect cucumber roots against oxidative stress induced by salt stress. Plant Physiol Biochem 45:542-550

Shigeoka S, Ishikawa T, Tamoi M, Miyagawa Y, Takeda T, Yabuta Y, Yoshimura K (2002) Regulation and function of ascorbate peroxidase isoenzymes. J Exp Bot 53:1305-1319

Singh HP, Batish DR, Kaur G, Arora K, Kohli RK (2008) Nitric oxide (as sodium nitroprusside) supplementation ameliorates $\mathrm{Cd}$ toxicity in hydroponically grown wheat roots.

Editorial responsibility: Brant Touchette,

Elon, North Carolina, USA
Environ Exp Bot 63:158-167

> Singh HP, Kaur S, Batish DR, Sharma VP, Sharma N, Kohli RK (2009) Nitric oxide alleviates arsenic toxicity by reducing oxidative damage in the roots of Oryza sativa (rice). Nitric Oxide 20:289-297

Stitt MS, Wasserloos KJ, Tang X, Liu X, Pitt BR, St Croix CM (2006) Nitric oxide-induced nuclear translocation of the metal responsive transcription factor MTF-1 is mediated by zinc release from metallothionein. Vascul Pharmacol 44:149-155

Stoyanova Z, Doncheva S (2002) The effect of zinc supply and succinate treatment on plant growth and mineral uptake in pea plant. Braz J Plant Physiol 14:111-116

Tewari RK, Hahn EJ, Paek KY (2008) Function of nitric oxide and superoxide anion in the adventitious root development and antioxidant defence in Panax ginseng. Plant Cell Rep 27:563-573

> Upadhyaya D, Sankhla TD, Davis N, Sankhla BN, Smith J (1985) Effect of paclobutrazol on the activities of some enzymes of activated oxygen metabolism and lipid peroxidation in senescing soybean leaves. Plant Physiol 121: 453-461

> Wang C, Zhang SH, Wang PF, Qian J, Hou J, Zhang WJ, Lu $\mathrm{J}$ (2009) Excess Zn alters the nutrient uptake and induces the antioxidative responses in submerged plant Hydrilla verticillata (L.f.) Royle. Chemosphere 76:938-945

> Wang C, Zhang SH, Li W, Wang P, Li L (2011) Nitric oxide supplementation alleviates ammonium toxicity in the submerged macrophyte Hydrilla verticillata (L.f.) Royle. Ecotoxicol Environ Saf 74:67-73

> Wang HH, Huang JJ, Bi YR (2010) Nitrate reductasedependent nitric oxide production is involved in aluminum tolerance in red kidney bean roots. Plant Sci 179: 281-288

> Wójcik M, Skórzynska-Poli E, Tukiendorf A (2006) Organic acids accumulation and antioxidant enzyme activities in Thlaspi caerulescens under $\mathrm{Zn}$ and Cd stress. Plant Growth Regul 48:145-155

Xiong J, Fu G, Tao L, Zhu C (2010) Roles of nitric oxide in alleviating heavy metal toxicity in plants. Arch Biochem Biophys 497:13-20

$>$ Xu J, Yin H, Li Y, Liu X (2010) Nitric oxide is associated with long-term zinc tolerance in Solanum nigrum. Plant Physiol 154:1319-1334

> Xu QS, Hu JZ, Xie KB, Yang HY, Du KH, Shi GX (2010) Accumulation and acute toxicity of silver in Potamogeton crispus L. J Hazard Mater 173:186-193

> Zhang Y, Wang L, Liu Y, Zhang Q, Wei Q, Zhang W (2006) Nitric oxide enhances salt tolerance in maize seedlings through increasing activities of proton-pump and $\mathrm{Na}^{+} \mathrm{H}^{+}$ antiport in the tonoplast. Planta 224:545-555

Submitted: April 22, 2014; Accepted: September 24, 2014

Proofs received from author(s): November 28, 2014 